\title{
Advanced Control of Liquid Water Region in Diffusion Media of Polymer Electrolyte Fuel Cells through a Dimensionless Number
}

\author{
Yun Wang ${ }^{\mathrm{a}^{*}}$ and Ken. S. Chen ${ }^{\mathrm{b}}$ \\ ${ }^{\mathrm{a} R e n e w a b l e ~ E n e r g y ~ R e s o u r c e s ~ L a b ~(R E R L) ~ a n d ~ N a t i o n a l ~ F u e l ~ C e l l ~ R e s e a r c h ~ C e n t e r ~}$ \\ Department of Mechanical and Aerospace Engineering \\ The University of California, Irvine \\ Irvine, CA 92697-3975, USA \\ ${ }^{\mathrm{b}}$ Sandia National Laboratories \\ Livermore, CA94550 USA \\ A revised manuscript submitted to J. Power Sources
}

Feb. 2016

*Corresponding Author

Email: yunw@uci.edu ; Phone: 949-824-6004; fax: 949-824-8585

(C) 2016. This manuscript version is made available under the Elsevier user license http://www.elsevier.com/open-access/userlicense/1.0/ 
Keywords polymer electrolyte fuel cells, phase change, non-isothermal, liquid water region, dimensionless number

In the present work, a three-dimension (3-D) model of polymer electrolyte fuel cells (PEFCs) is employed to investigate the complex, non-isothermal, two-phase flow in the gas diffusion layer (GDL). Phase change in gas flow channels is explained, and a simplified approach accounting for phase change is incorporated into the fuel cell model. It is found that the liquid water contours in the GDL are similar along flow channels when the channels are subject to two-phase flow. Analysis is performed on a dimensionless parameter $\mathrm{Da}_{0}$ introduced in our previous paper [Y. Wang and K. S. Chen, Chemical Engineering Science 66 (2011) 3557-3567] and the parameter is further evaluated in a realistic fuel cell. We found that the GDL's liquid water (or liquid-free) region is determined by the $\mathrm{Da}_{0}$ number which lumps several parameters, including the thermal conductivity and operating temperature. By adjusting these factors, a liquid-free GDL zone can be created even though the channel stream is two-phase flow. Such a liquid-free zone is adjacent to the two-phase region, benefiting local water management, namely avoiding both severe flooding and dryness. 


\section{Introduction}

Water management is a central issue in the development of polymer electrolyte fuel cells (PEFCs): liquid water may considerably increase the oxygen transport resistance and hence the transport polarization whereas dryness dehydrates the electrolyte membrane, raising the Ohmic voltage loss. PEFCs produce water during operation and the electro osmosis enlarges the water imbalance between the anode and cathode sides, making water management a complex operation that requires a careful treatment. Issues such as diffusion media dewetting, anode rehydration, and internal humidification have received much attention in recent years [1]. Modeling and numerical simulation are capable of revealing details of transport phenomena, and is a powerful tool for elucidating water management.

Modeling two-phase transport in PEFCFs is an active area of research [1-5]. Springer et al. [6], Nguyen and White [7], Fuller and Newman [8], and Bernardi and Verbrugge [9], to name just a few, represent an early pioneering effort dated back in 1990s. In their studies, the through-plane direction is the focus with both electrochemical and transport activities accounted for. Multi-dimensional models, based on conservation equations (continuity, fluid flow, energy and so on) in conjunction with electrochemical reactions, were attempted by later studies such as the two-dimensional models of Yi and Nguyen [10] and Gurau et al. [11] and the three dimensional models of Dutta et al. [12], Zhou and Liu [13], Berning et al. [14], Mazumber and Cole [15], Um and Wang [16] and Wang and Wang [17], to name just a few. These models mostly neglected liquid water formation and transport and assumed water exists in a super saturated state. Two-phase models were developed by He et al. [18], Natarajan and Nguyen [19], Berning and Djilali [20], Mazumber and Cole [21], Wang and co-workers [22-24], You and Liu [25], Hu and Fan [26], 
and Webber and Newman [27], to name just a few. They considered vapor and liquid water move at different velocities. Other liquid water behaviors including the surface tension and flooding effects were also taken into account. Liquid water originates from water production by fuel cell electrochemistry. When fed-in reactants are dry, no liquid will appear at the beginning. As the water vapor is saturated down the channel, vapor condensation takes place, leading to liquid water formation. Capturing the point where two-phase flows emerge is important because the portion further downstream this onset point requires liquid water removal, as described by Luo et al. [28] and Wang [29], which numerically captured the regime of two-phase flow downstream. In the in-plane direction, water produced under the solid lands must reach the channel stream in order to be removed. Wang and Chen [30] investigated the liquid water profiles in both through-plane and in-plane direction and validated their predictions against experimental data, showing how GDL property spatial variation and land compression influence liquid water distribution. Most of previous modeling studies excluded the channel two-phase flow and phase change. In the channel, liquid will accumulate along the flow direction due to water production and two-phase flow plays an important role in fuel cell operation [31-35]. Wang et al. [36] and Wang [37] modeled the two-phase flow in the along-channel direction, and analytically obtained the liquid saturation profiles in channels. The model [37] was further adopted to compare with experimental measurements for both hydrophilic and hydrophilic-hydrophobic micro channels [38,39]. In addition to two-phase flow, droplet formation at the cathode GDL/channel interface may greatly impact fuel cell performance [40-44]. At the microscale, transport in GDLs takes place in the interconnected pore structure. Pore-level transport in GDLs was modeled and investigated by Sinha et al. [45], Park and Li [46], and Wang et al. [47], to name just a few. In the two-phase regime, the heat pipe effect may occur and 
contribute to both water and heat removals [5,48,49]. Wang and Gundevia [48] carried out experiments in which heat pipe effect in carbon paper was measured and the impact of material wetting property was evaluated.

Though modeling has been attempted by various groups to study fuel cell operation and two-phase transport, little has been done to identify dimensionless parameters that characterize two-phase flow in a fuel cell. In our previous analysis [50], we identified a dimensionless parameter $\mathrm{Da}_{0}$ which characterizes the in-plane two-phase regime. When $\mathrm{Da}_{0}$ is over 1 , part of the GDL region is free of water due to waste heat production and evaporation. This paper examines the $\mathrm{Da}_{0}$ number in a real fuel cell operation; especially, we will examine the $\mathrm{Da}_{0}$ definition in a realistic fuel cell and its value along the gas flow channel. A liquid-free GDL region is defined and related to $\mathrm{Da}_{0}$ with its benefits discussed. Impacts of operating temperatures, GDL thermal conductivities, and current densities on the region are discussed as well. 


\section{Theory}

\subsection{Along-channel water management}

There is a dilemma in water management along gas flow channel: the inlet area may be subjected to dryness (when dry reactants are fed in) whereas there is a "flooding" issue near the outlet due to water production by the oxygen reduction reaction or ORR. Any strategies that alleviate the former likely worsen the latter, and vice versa. Down the channel, the reactant stream picks up water molecules from the ORR's production and increases its water content. When the stream reaches its saturated level, liquid water emerges, leading to two-phase flow. Liquid water in GDLs narrows the passage of oxygen transport toward the catalyst layer (CL), increasing transport resistance. Another issue is the liquid coverage on the GDL surface which hampers oxygen access to the reaction sites. Furthermore, the ORR is sluggish, exhibiting a large concentration loss under high current density. In this regard, liquid-free operation reduces the concentration loss by avoiding liquid blockage/narrowing of the oxygen transport passage. Dryness operation, however, leads to electrolyte dehydration, increasing the Ohmic voltage loss and raising material degradation or durability concerns.

\section{2 $\mathrm{Da}_{0}$ along gas flow channels}

Water and waste heat are added to cathode GDL from CL. Water is then removed by channel gas flows; and most waste heat is taken away via lands. A dimensionless number $\mathrm{Da}_{0}$ as defined in our previous paper [50], describes the relative importance of water addition rate to water removal rate: 


$$
\begin{gathered}
\mathrm{Da}_{0}=\frac{\text { Rate of water addition }}{\text { Rate of water removal via diffusion and evaporation }} \\
=\frac{k_{G D L, H}^{e f f}(1+2 \alpha)}{f_{\max } F D_{w}^{e f f}\left(E_{o}-V_{c e l l}\right) \frac{d C_{s a t}^{w}\left(T_{0}\right)}{d T}}\left(1+\frac{1}{S h} \frac{H_{c h} D_{w}^{e f f}}{H_{G D L} D_{w}}\right)
\end{gathered}
$$

In the above, the Sherwood number, $\operatorname{Sh}\left(=\frac{h_{m} H_{c h}}{D_{w}}\right)$, is determined by the mass transfer in gas flow channels. Mass transfer in micro channel, analogous to momentum/heat transfer, varies in the entrance length, but remains constant in the fully developed region. In the momentum transfer, the entrance region is where the boundary layer develops near the channel walls before meeting at the centerline. For laminar flow in tubes, the entrance length is about 5 times of the channel diameter (L/D Re/20) for Re 100 which occurs in fuel cell channels. In this case, the length is about $2.5-10 \mathrm{~mm}$ and after that the channel stream is fully developed. In the fully developed portion, water enters the channel from the CL's ORR production and transports across the channel and condenses over the channel's cold surface, see Fig. 1 (a). Assuming the axial velocity remains constant and diffusion is the dominant through-plane transport mechanism in gas flow channel, the water flux via the vapor phase can be evaluated by:

$$
G_{w, \text { diff }, \text { max }}=\frac{\Delta C_{s a t}^{w}+C_{s a t}^{w}\left(T_{0}\right)-C_{c h, w a l l}^{w}}{\frac{H_{G D L}}{D_{w}^{e f f}}+\frac{H_{c h}}{D_{w}}}=\frac{\Delta C_{s a t}^{w}+C_{s a t}^{w}\left(T_{0}\right)-C_{c h, w a l l}^{w}}{\frac{H_{G D L}}{D_{w}^{e f f}}\left(1+\frac{H_{c h} D_{w}^{e f f}}{H_{G D L} D_{w}}\right)}
$$

where $C_{c h, w a l l}^{w}$ is the vapor concentration at the channel bottom wall against the GDL. When the channel stream is two-phase flow, $C_{c h \text {,wall }}^{w}$ can be approximated to the vapor saturated concentration determined by local temperature. In addition, we assume the 
Sherwood number is equal to 1 . In the absence of along-channel temperature variation, $C_{c h, w a l l}^{w}$ remains constant. Though defined for local GDL, the $\mathrm{Da}_{0}$ number is also applicable to the entire GDL under the channel. Several factors affect the $\mathrm{Da}_{0}$ number, including local self-heating, which is determined by local current density, interfacial overpotential and Ohmic resistance, the net water transport coefficient, GDL thermal conductivity, and temperature. Both self-heating and net water transport coefficient vary down the flow channel, but change within an order of magnitude. Other factors, such as temperature and GDL thermal conductivity, can significantly impact $\mathrm{Da}_{0}$, e.g. several folds, which provides an effective way to practically control the GDL two-phase region. Fig. 2 shows the profiles of $\frac{d C_{s a t}^{w}}{d T}$ and $C_{s a t}^{w}$, indicative of their exponential dependence on temperature. As an example, the derivative $\frac{d C_{\text {sat }}^{w}}{d T}$ is about 0.3 at $60{ }^{\circ} \mathrm{C}$, and around 0.8 at $90{ }^{\circ} \mathrm{C}$. 


\section{Mathematical Modeling}

\subsection{Governing equations}

To capture the phenomena in fuel cells, the mathematical model to be adopted accounts for the major electrochemical and transport mechanisms in the major components, including the catalyst layers and membrane, gas diffusion layer, gas flow channel, and bipolar plates. The governing equations are formulated through the conservation of mass, momentum, species, charges, and energy, and can be presented in a general form as follow:

Continuity equation: $\quad \nabla \cdot(\rho \vec{u})=0$

Momentum conservation: $\quad \frac{1}{\varepsilon^{2}} \nabla \cdot(\rho \vec{u} \vec{u})=-\nabla P+\nabla \cdot \rho \tau+S_{u}$

Energy conservation: $\quad \nabla \cdot\left(\gamma_{T} \rho c_{p} \vec{u} T\right)=\nabla \cdot\left(k^{e f f} \nabla T\right)+S_{T}$

Reactant species conservation: $\quad \nabla \cdot\left(\gamma_{k} \vec{u} C^{k}\right)=-\nabla \cdot \vec{G}_{k, \text { diff }}+S_{k}$

Water conservation:

$$
\nabla \cdot\left(\gamma_{w} \vec{u} C^{w}\right)=-\nabla \cdot\left(\vec{G}_{w, \text { diff }}+\vec{G}_{w, p e r m}\right)-\nabla \cdot\left[\left(\frac{m f_{l}^{w}}{M^{w}}-\frac{C_{g}^{w}}{\rho_{g}}\right) \vec{j}_{l}\right]+S_{w}
$$

Charge conservation (protons): $\quad 0=\nabla \cdot\left(\sigma_{m}^{\text {eff }} \nabla \Phi^{(m)}\right)+S_{\Phi^{(m)}}$

Charge conservation (electrons): $\quad 0=\nabla \cdot\left(\sigma_{s}^{e f f} \nabla \Phi^{(s)}\right)+S_{\Phi^{(s)}}$

where $\rho$ the multiphase mixture density, $\vec{u}$ the superficial fluid velocity vector, $p$ the pressure, $C^{k} / C^{w}$ the molar concentration of reactant/water, T the temperature, $\Phi^{(m)} /$ $\Phi^{(s)}$ the electronic/electrolyte phase potentials. $\vec{G}_{\text {diff }}$ denotes the diffusion fluxes in gaseous, liquid and solid electrolyte phases. $\vec{G}_{w, \text { perm }}$ represents the hydraulic permeation water flux through the membrane. The electrochemical and transport processes are coupled together through the model parameters and source terms. The physical properties, source terms, and electrochemical reaction kinetics are listed in Tables 1-3. 
Details regarding the above adopted model can be found in our previous work $[24,29,30]$ and the review paper [1,2]. Specially, the M2 (multiphase mixture) formula [2,5] is employed in the regions of catalyst layer and GDL; and the nonisothermal two-phase model accounts for both the vapor phase diffusion and heat pipe effect [24]. The model is capable of capturing the boundary between the single- and two-phase flows regions [29], which is key to investigating the liquid region in GDLs. In the gas flow channel, we assume the liquid phase exists in tiny droplets travelling with gas flow without impacts on the gas-phase flow. Phase change at the colder wall surface (which accounts for most water condensation) is incorporated into the channel model. At the GDL/GC interface, because of lack of the data for the liquid coverage on GDL surface, zero liquid coverage is assumed. In the electrolyte membrane, the hydraulic permeation is taken into account [29]. In addition, we neglect the micropore layers (MPL) between the MEA and GDLs and assume a sufficiently large flow rate of coolant flow (which renders the bipolar outer surface at constant temperature) to better elucidate the physical phenomena occurring in the GDLs. The phase change in the gas flow channel is set as a boundary condition, which will be elaborated in the next section. Note that this paper is not to precisely address the complicate two-phase flow in gas flow channels or flow interaction, instead it aims to explain the consequence of phase change in the channel which is key to capture the GDL two-phase flow region.

\subsection{Phase change (condensation) at the channel surface}


In GFCs, liquid water emerges as the vapor partial pressure reaches the saturated level. Assuming no supersaturated state exists, condensation will occur at the cold wall surface of channels. The local phase-change rate can be formulated by [50, 51]:

$$
\vec{G}_{w, d i f f}^{w}=-D_{g}^{w} \frac{\partial C_{g}^{w}}{\partial \vec{n}}=-h_{m}\left(C_{c h}^{w}-C_{c h, w a l l}^{w}\right) \vec{n}
$$

where $\vec{n}$ is the normal unit vector outward the targeted surface; and $C_{c h}^{w}$ and $C_{c h, w a l l}^{w}$ the mean vapor concentration in the channel stream and vapor concentration at the channel's bottom surface, respectively. When liquid water is present at the channel surface, $C_{c h \text {,wall }}^{w}$ is assumed as the saturated vapor concentration determined by local temperature. The mass transfer coefficient, $\mathrm{h}_{\mathrm{m}}$, is determined by the Sherwood number $\left(\mathrm{Sh}=\frac{h_{m} H_{c h}}{D_{w}}\right)$. In the fully developed region, Sh can be assumed constant, 3.66 [50]. Koz and Kandlikar found Sh to be 3.36 using 3D simulation [52].

Due to condensation, a flux of the latent heat release associated with phase change is given by:

$$
-\vec{\Gamma}_{T, f g}=-D_{g}^{w} \frac{\partial C_{g}^{w}}{\partial \vec{n}} h_{f g}
$$

where $\vec{\Gamma}_{T, f g}$ denotes the heat flux along the vector $\vec{n}$ due to phase change. Note that the above two equations are the boundary conditions of water and heat arising from the phase change at the channel surface.

\subsection{Boundary conditions}


Eq. (3) forms a complete set of governing equations with nine unknowns: $\vec{u}, P, C^{k}, C^{w}$, $\mathrm{T}, \Phi^{(m)}$, and $\Phi^{(s)}$. The boundary condition arising from phase change in the channel region is explained in the preceding section. Other corresponding boundary conditions are briefly described below.

Flow inlet boundary: The inlet velocity $\vec{u}_{i n}$ in a gas channel is expressed by the respective anode or cathode stoichiometric flow ratio, i.e., $\xi_{a}$ or $\xi_{c}$, defined using the average current density $I$ as:

$$
\left.\left(\begin{array}{l}
\vec{u}_{i n, a} \\
\vec{u}_{i n, c}
\end{array}\right) \cdot \vec{n}\right|_{\text {inlet }}=-\left.\frac{I A_{m}}{F}\left(\begin{array}{c}
\frac{\xi_{a}}{2 C^{H 2} A_{a}} \\
\frac{\xi_{c}}{4 C^{O 2} A_{c}}
\end{array}\right)\right|_{\text {inlet }}
$$

where $A_{a}, A_{c}$,and $A_{m}$ are the flow cross-sectional areas of the anode and cathode gas channels and the membrane, respectively. The inlet molar concentrations are determined by the inlet pressure and humidity according to the ideal gas law.

Outlet boundary: Fully developed or no-flux conditions are applied.

Walls: No-slip and impermeable velocity condition and no-flux condition are imposed for the mass, momentum, proton and species (excluding water) conservation equations. The boundary conditions for the electronic phase potential $\Phi^{(s)}$ and temperature $\mathrm{T}$ at the bipolar plate outer surfaces are expressed as:

$$
\left.\frac{\partial \Phi^{(s)}}{\partial n}\right|_{\text {cathode }}=-\frac{I A_{m}}{\sigma^{\text {eff }} A_{c, \text { wall }}} ;\left.\Phi^{(s)}\right|_{\text {anode }}=0 ;\left.T\right|_{\text {anodel cathode }}=T_{0}
$$


where $A_{c, \text { wall }}$ is the cathode outer surface area. At other wall surfaces, symmetry conditions apply for both $\mathrm{T}$ and $\Phi^{(s)}$.

\subsection{Numerical procedures}

The governing equation Eq. (3) along with its boundary conditions is discretized by the finite volume method and solved in the commercial CFD software package, Fluent ${ }^{\circledR}$ (version 6.0.12), by SIMPLE (semi-implicit method for pressure linked equation) algorithm. The SIMPLE algorithm updates the pressure and velocity fields from the solution of a pressure correction equation, solved by the algebraic multi-grid (AMG) method. Following the solution of the flow equation, energy, species, proton, and electron equations are solved. The source terms and physical properties are implemented in a UDF (user-defined function) and the species and charge transport equations are solved through the software's user-defined scalars. The mesh of a single-channel PEFC employed for the numerical study is shown in Fig. 1 (b). The computational domain, including the number of the computational cells in each dimension, is similar to our previous published work [30]. Geometrical and operating parameters are listed in Table 1. In all the simulations to be presented in the next section, values of species imbalance (i.e. $\mathrm{H}_{2}, \mathrm{O}_{2}$ and $\mathrm{H}_{2} \mathrm{O}$ ) are all less than $1 \%$ and equation residuals smaller than $10^{-6}$. 


\section{Results and Discussion}

Figure 3 (i) displays the liquid saturation distributions in the GDL at the 10\%, 50\% and $90 \%$ channel lengths from the inlet, respectively, under $80^{\circ} \mathrm{C}$ operating temperature. For the three typical locations, liquid is predicted to appear under the land and in part of the GDL under the cathode channel but it is not present under the anode channel. In the cathode, the saturation reaches as high as $20 \%$, and is reduced to almost 0 near the centerline of the channel. As water is produced in the cathode CL, liquid also appears near the cathode CL under the channel. Though the predicted liquid content is low $(<20 \%)$, the model excludes residual liquid water, which may exist randomly throughout the two-phase region and can only be removed through evaporation. Residual water can be trapped by the pore-network structure (e.g. a big pore with small throats or fiber connection sites) or surface heterogeneity (e.g. a hydrophilic region surrounded by hydrophobic one). It is, however, difficult to incorporate residual water mechanism into a macroscopic model, because the latter usually neglects micro-structural features of porous media. Wang and Chen [30] explained local GDL heterogeneity in both structure and surface wettability, showing such property may lead to local water trap. Hickner et al. [53] indicated that residual water can be significant in GDLs, based on a neutron radiography study. Fig. 4 directly displays liquid water formation in catalyst layer, MPL, and gas diffusion layer, indicating that liquid appears randomly in the microstructure of these media. When subject to unsaturated or dry surrounding, liquid can be removed through evaporation.

Figure 3 (ii) displays the temperature contours at the same locations. A similar trend is shown for the three locations and the peak temperature all appear under the 
channel. The "hot" region under the channel increases the evaporation rate of local liquid water, which may yield a liquid-free zone. Fig. 3 (ii) shows that an approximate $1 \mathrm{~K}$ change is indicated within the GDL. However, evaporation is not strong enough to remove all the water added to the cathode, as shown in Fig. 3 (i). In addition, the nearinlet location exhibits the highest peak temperature because the local current density is high (to be shown later). Though the peak temperatures are different among the three locations, the liquid contents in the CL are similar. This can be explained by the fact that current density does not appear explicitly in the $\mathrm{Da}_{0}$ expression. The local $\mathrm{Da}_{0}$ profile along the channel will be given later.

Eq. (1) shows that the GDL conductivity affects the $\mathrm{Da}_{0}$ number. Figure 3 (iii) displays the temperature contours under a reduced thermal conductivity, $1 \mathrm{~W} / \mathrm{m} \mathrm{K}$. Due to heat transport resistance increase, the peak temperature increases with the maximum by about $1.75 \mathrm{~K}$, as seen in the CL. Note that higher temperature will increase local evaporation rate. The liquid saturation distributions are presented in Figure 3 (iv), showing that the liquid region diminishes at all the three locations, specially part of the cathode CL under the channel is free of liquid. In the liquid-free GDL region, the vapor phase is below the saturated value, therefore no residual liquid exists at equilibrium. Due to adjacency to a two-phase region, the liquid-free region remains highly humidified, avoiding dryness.

Another factor that alters the $\mathrm{Da}_{0}$ value is operating temperature. Figure 5 (i) presents the liquid water distributions under $60{ }^{\circ} \mathrm{C}$ and with the GDL conductivity of 1.7 $\mathrm{K} / \mathrm{m} \mathrm{K}$. The GDL's two-phase region is considerably increased, comparing with Fig. 3 (i): most cathode GDL contains certain liquid content. Figure 5 (ii) presents the liquid 
water distribution under $90{ }^{\circ} \mathrm{C}$ and with the same conductivity, showing the wet region considerably diminishes in comparison with Fig. 3 (i) and Fig. 5 (i). Even in the cathode $\mathrm{CL}$ where water is produced, no liquid water is present. Note that in all the cases, we consider liquid water appears on the cathode channel wall.

Figure 6 displays the vapor and temperature distributions at the channel's centerline. In the cathode channel, the vapor concentration varies little down the channel, as we consider two-phase channel flow. The vapor concentration is higher near the inlet, which can be explained by higher local current density in favor of abundant oxygen. Further, Fig. 6 (a) shows that only a very small GDL region near the inlet has liquid water, while most GDL area is free of liquid as the local vapor is yet saturated. Figure 6 (b) displays the temperature contours, showing that high GDL temperature appears near the inlet. In the outlet region, an approximate $364.15 \mathrm{~K}$ is shown in the CL, with the corresponding saturated vapor content about $23.7 \mathrm{~mol} / \mathrm{m}^{3}$, which is higher than the vapor content in most GDL area as shown in Figure 6 (a).

Figure 7 (i) plots the net water transfer coefficient $\alpha$ distribution along the channel, and shows that its value varies greatly in the in-plane direction but changes little in the along-channel direction. The observed small along-channel variation is attributed to the saturated channel stream (thus almost constant vapor concentration along the channel). The $\mathrm{Da}_{0}$ number can be calculated based on the in-plane average $\alpha$ over the channel region:

$$
\bar{\alpha}=\frac{1}{L_{z}} \int_{0}^{L_{z}} \alpha d z
$$


Using the average value is physically sound because water transport occurs in the lateral direction as well, thus local accumulated water under a higher $\alpha$ region can transport to the region that has lower $\alpha$. Note that the local current density changes significantly from the inlet to outlet, as shown in Fig. 7 (ii). A decease trend from inlet to outlet and from channel to land, respectively, is shown for all the three cases, indicative of oxygen depletion down the channel and oxygen transport resistance enlarged by the land presence.

The $\mathrm{Da}_{0}$ profiles along the channel, based on the average $\alpha$, are plotted in Figure 8. It can be seen that the $\mathrm{Da}_{0}$ number varies little along the channel in most of the region except near the inlet. For $0.5 \mathrm{~A} / \mathrm{cm}^{2}$, the inlet region exhibits a slightly higher $\mathrm{Da}_{0}$. This is likely due to the fact that the inlet region is in favor of abundant oxygen therefore exhibiting a higher local current density and a smaller $\alpha$ as shown in Fig. 7. For $90{ }^{\circ} \mathrm{C}$ and $0.5 \mathrm{~A} / \mathrm{cm}^{2}$, part of the inlet region has $\mathrm{Da}_{0}$ over 1 , which is consistent with the liquid water distributions shown in Figures 5 (ii) and 6 (a).

Our previous study [50] indicates that higher current density may yield a larger single-phase GDL area. This can be explained by the increased voltage loss (and hence self-heating) as shown in the expression of the $\mathrm{Da}_{0}$ number (Eq. 1). Figure 8 also plots the $\mathrm{Da}_{0}$ profile along channels under $90{ }^{\circ} \mathrm{C}$ and $1 \mathrm{~A} / \mathrm{cm}^{2}$. It can be seen that the $\mathrm{Da}_{0}$ number is less than 1 in the entire region. The near inlet region has a lower value of $\mathrm{Da}_{0}$, which is different with the one under $0.5 \mathrm{~A} / \mathrm{cm}^{2}$, indicating the complex water transport across the membrane. Figure 5 (iii) shows the liquid water distribution under $90{ }^{\circ} \mathrm{C}$ and 1 $\mathrm{A} / \mathrm{cm}^{2}$. For the three locations, the GDL near the channel centerline is free of liquid water, consistent with Fig. 8. Figure 5 (iv) displays the temperature contours at the same 
locations. Though the contours are similar to those in the $0.5 \mathrm{~A} / \mathrm{cm}^{2}$ cases, the peak temperature is much higher, which is the main reason for the observed enlarged liquidfree GDL region. 


\section{Conclusions}

In the present work, the two-phase transport and liquid-free regions in the cathode GDL was investigated through a 3-D numerical study. Phase change in gas flow channels was elucidated and its effect was taken into account. Following a dimensionless parameter, $\mathrm{Da}_{0}$, as defined in our previous study, we extended the discussion for practical fuel cell channels for fully developed and saturated vapor phase condition. The $\mathrm{Da}_{0}$ was further defined based on the in-plane averaged $\alpha$ to characterize the in-plane two-phase regime under flow channels. When the gas channel flow is two-phase stream and no supersaturated state exists, the channel vapor content remains almost constant along the channel, thus $\mathrm{Da}_{0}$ varies little. For $\mathrm{Da}_{0}$ below 1 , a liquid-free region near the channel centerline exists for the portion of the gas channel in two-phase flow regime. We also found that the GDL thermal conductivity and operating temperatures greatly affect the $\mathrm{Da}_{0}$ value. Thus, their dependence can be explored for controlling the liquid-free region through careful design: under the studied cases of $90{ }^{\circ} \mathrm{C}$ or low GDL thermal conductivity $(1.0 \mathrm{~W} / \mathrm{m} \mathrm{K})$, we successfully predicted a liquid-free region in the cathode GDL and CL near the channel centerline. In addition, we explored high current density operation, which results in a large area liquid-free region due to increased cell voltage loss. The benefits of creating such a GDL liquid-free region were also explained, which avoids the presence of residual liquid water (and associated "flooding" concern) and severe dryness. The finding is important for practical water management and operation strategy/fuel cell design to achieve better fuel cell performance and alleviate flooding/dryness-associated degradation. 


\section{Acknowledgements}

Funding support of this work was provided by Sandia National Laboratories (through a fuel cell project funded by US Department of Energy's EERE Program and titled "Development and Validation of a Two-phase, Three-dimensional Model for PEM Fuel Cells"). Sandia is a multiprogram laboratory operated by Sandia Corporation, a Lockheed Martin Company for the United States Department of Energy's National Nuclear Security Administration under contract no. DE-AC04-94AL85000. 
C molar concentration, $\mathrm{mol} / \mathrm{m}^{3}$

D mass diffusivity of species, $\mathrm{m}^{2} / \mathrm{s}$

Da the Damköhler number

F Faraday's constant, 96,487 C/equivalent

$\vec{G} \quad$ species diffusion/permeation flux, $\mathrm{mol} \mathrm{m} \mathrm{m}^{-2}$

I current density, $\mathrm{A} / \mathrm{cm}^{2}$

$\vec{i} \quad$ superficial current density, $\mathrm{A} \mathrm{cm}^{-2}$

$j \quad$ transfer current density, $\mathrm{A} \mathrm{cm}^{-3}$

$\vec{j}^{(l)} \quad$ mass flux of liquid phase, $\mathrm{kg} \mathrm{m}^{-2} \mathrm{~s}^{-1}$

$K \quad$ permeability, $\mathrm{m}^{2}$

M molecular weight, $\mathrm{kg} / \mathrm{mol}$

$\mathrm{P} \quad$ pressure, $\mathrm{Pa}$

R gas constant, $8.134 \mathrm{~J} / \mathrm{mol} \mathrm{K}$

S liquid saturation

S source term

$\mathrm{T}$ temperature, $\mathrm{K}$

$U_{o} \quad$ equilibrium potential, $\mathrm{V}$

$\vec{u} \quad$ velocity vector, $\mathrm{m} / \mathrm{s}$

\section{Greek}

$\alpha \quad$ net water transport coefficient per proton

$\varepsilon \quad$ porosity 


$$
\begin{array}{ll}
\Phi & \text { phase potential, } \mathrm{V} \\
\overrightarrow{\vec{\tau}} & \text { shear stress, } \mathrm{N} \mathrm{m}^{-2} \\
v & \text { kinematic viscosity, } \mathrm{m}^{2} / \mathrm{s} \\
\sigma & \text { surface tension, } \mathrm{N} / \mathrm{m} \\
\rho & \text { density, } \mathrm{kg} / \mathrm{m}^{3} \\
\gamma_{c} & \text { correction factor for species convection } \\
\eta & \text { surface overpotential, } \mathrm{V}
\end{array}
$$

\section{Superscripts and Subscripts}
a anode
c cathode
Ch channel
d electro osmotic drag
eff effective value
GDL gas diffusion layer
g gas phase
k species; liquid or gas phase
$l \quad$ liquid
m membrane
perm permeation
sat saturate value
s liquid saturation or solid phase 


\section{References}

1. Y. Wang, K.S. Chen, J. Mishler, S.C. Cho, and X.C. Adroher, "A Review of Polymer Electrolyte Membrane Fuel Cells: Technology, Applications, and Needs on Fundamental Research”, Applied Energy 88 (2011) 981-1007.

2. C.Y. Wang, Chemical Reviews, 104, 4727 (2004).

3. A. Z. Weber and J. Newman, Chemical Reviews, 104, 4679 (2004).

4. K. Jiao and X. Li. "Water transport in polymer electrolyte membrane fuel cells." Progress in Energy and Combustion Science 37.3 (2011): 221-291.

5. Y. Wang, K.S. Chen, and S. C. Cho, PEM Fuel Cells: Thermal and Water Management Fundamentals (Sustainable Energy), Momentum Press (2013)

6. T.E. Springer, T.A. Zawodinski, S. Gottesfeld, J. Electrochem. Soc. 138, 23342341 (1991).

7. T. V. Nguyen and R. E. White, "A water and heat management model for protonexchange-membrane fuel cells", J. Electrochem. Soc. 140, 2178 (1993).

8. T. F. Fuller and J. Newman, "Water and thermal management in solid-polymerelectrolyte fuel cells", J. Electrochem. Soc. 140, 1218 (1993).

9. D. M. Bernardi, and M. W. Verbrugge, "A mathematical model of the solidpolymer-electrolyte fuel cell”, J. Electrochem. Soc., 139, 2477 (1992).

10. J. S. Yi, and T. V. Nguyen, "An along-the-channel model for proton exchange membrane fuel cells", J. Electrochem. Soc., 145, 1149 (1998). 
11. V. Gurau, H. Liu, and S. Kakac, "Two-dimensional model for proton exchange membrane fuel cells", AIChE J., 44, p. 2410 (1998).

12. S. Dutta, S. Shimpalee, and J. W. Van Zee, "Three-dimensional numerical simulation of straight channel PEM fuel cells", J. Appl. Electrochem., 30, p. 135 (2000).

13. T. Zhou and H. Liu, "A general three-dimensional model for proton exchange membrane fuel cells", Int. J. Transport Phenomena 3, 177 (2001).

14. T. Berning, D. M. Lu, and N. Djilali, "Three-dimensional computational analysis of transport phenomena in a PEM fuel cell”, J. of Power Sources, V.106, p.284-294 (2002).

15. S. Mazumder and J. V. Cole, "Rigorous 3-D mathematical modeling of PEM fuel cells. II. Model predictions without liquid water transport", J. Electrochem. Soc., 150, A1503-A1509 (2003).

16. S. Um, C.-Y. Wang, and K. S. Chen, "Computational fluid dynamics modeling of proton exchange membrane fuel cells", J. Electrochemical Society, V.147, p. 44854493 (2000).

17. Y. Wang and C.Y. Wang, "Modeling polymer electrolyte fuel cells with large density and velocity changes", J. Electrochem. Soc., Vol.152, pp.A445-A453 (2005).

18. W. He, J. S. Yi, and T. V. Nguyen, "Two-phase flow model of the cathode of PEM fuel cells using interdigitated flow fields", AIChE J., 46(10), 2053-2064 (2000). 
19. D. Natarajan, and T. V. Nguyen, "A two-dimensional, two-phase, multicomponent, transient model for the cathode of a proton exchange membrane fuel cell using conventional gas distributors", J. Electrochem. Soc., 148, A1324-A1335 (2001).

20. T. Berning and N. Djilali, "A 3D, multiphase, multicomponent model of the cathode and anode of a PEM fuel cell”, J. Electrochem. Soc., 150, A1589-A1598 (2003).

21. S. Mazumder and J. V. Cole, "Rigorous 3-D mathematical modeling of PEM fuel cells. II. Model predictions with liquid water transport”, J. Electrochem. Soc., 150, A1510-A1517 (2003).

22. Z.H. Wang, C.Y. Wang and K.S. Chen, J. Power Sources, 94, 40-50 (2001).

23. U. Pasaogullari and C.Y. Wang, "Liquid water transport in gas diffusion layer of polymer electrolyte fuel cells", J. Electrochem. Soc., Vol.151, pp.A399-A406 (2004).

24. Y. Wang and C.Y. Wang, "A non-isothermal, two-phase model of polymer electrolyte fuel cells”, J. Electrochem. Soc., Vol.153, pp.A1193-A1200 (2006).

25. L. You and H. Liu, "A two-phase flow and transport model for the cathode of PEM fuel cells", Int. J. Heat Mass Transfer, 45, 2277-2287 (2002).

26. G. L. Hu and J. R. Fan, “A three-dimensional, multicomponent, two-phase model for a proton exchange membrane fuel cell with straight channels", ENERGY \& FUELS, V. 20, p. 738 (2006).

27. A. Z. Weber, R. M. Darling, and J. Newman, "Modeling Two-Phase Behavior in PEFCs," J. Electrochem. Soc., 151, A1715 (2004). 
28. G. Luo, H. Ju and C.Y. Wang, "Prediction of dry-wet-dry transition in polymer electrolyte fuel cells”, J. Electrochem. Soc., Vol.154, pp. B316-321 (2007).

29. Y. Wang, J. Power Sources, 185, 261-271 (2008).

30. Y. Wang and K. S. Chen, Effect of Spatially-Varying GDL Properties and Land Compression on Water Distribution in PEM Fuel Cells, J. Electrochem. Soc. 158 (11) B1292-B1299 (2011).

31. S.V. Garimella, C.B. Sobhan, Transport in microchannels - A critical review, Annu. Rev. Heat Transfer 13 (2003) 1-50.

32. R. Anderson, L. Zhang, Y. Ding, M. Blanco, X. Bi, D.P. Wilkinson, A critical review of two-phase flow in gas flow channels of proton exchange membrane fuel cells, J. Power Sources 195 (15) (2010) 4531-4553.

33. S.G. Kandlikar, E.J. See, M. Koz, P. Gopalan, and R. Banerjee, "Two-phase flow in GDL and reactant channels of a proton exchange membrane fuel cell", International journal of hydrogen energy 39.12 (2014): 6620-6636.

34. M. Hossain, S.Z. Islam, A. Colley-Davies, and E. Adom, "Water dynamics inside a cathode channel of a polymer electrolyte membrane fuel cell." Renewable Energy 50 (2013): 763-779.

35. M.J. Cheah, I.G. Kevrekidis, J.B. Benziger, "Water slug to drop and film transitions in gas-flow channels." Langmuir, 29.48 (2013): 15122-15136.

36. Y. Wang, S. Basu and C.Y. Wang, "Modeling two-phase flow in PEM fuel cell channels", J Power Sources, Vol.179, 603-617 (2008).

37. Y. Wang, J. Electrochem. Soc., 156 (10) B1134-B1141 (2009). 
38. S. C. Cho, and Y. Wang "Two-phase flow dynamics in a micro channel with heterogeneous surfaces." International Journal of Heat and Mass Transfer 71 (2014): 349-360.

39. S. C. Cho, and Y. Wang, "Two-phase flow dynamics in a micro hydrophilic channel: A theoretical and experimental study." International Journal of Heat and Mass Transfer 70 (2014): 340-352.

40. S. C. Cho, Y. Wang, and K.S. Chen, Droplet dynamics in a polymer electrolyte fuel cell gas flow channel: Forces, deformation, and detachment. I: Theoretical and numerical analyses, Journal of Power Sources 206 (2012) 119-128.

41. S. C. Cho, Y. Wang, and K.S. Chen, Droplet dynamics in a polymer electrolyte fuel cell gas flow channel: Forces, Deformation and detachment. II: Comparisons of analytical solution with numerical and experimental results, Journal of Power Sources, 210 (2012) 191-197.

42. K.S. Chen, M.A. Hickner, D.R. Noble, Int. J. Energy Res. 29 (2005) 1113-1132.

43. E.C. Kumbur, K.V. Sharp, M.M. Mench, J. Power Sources 161 (2006) 333-345.

44. A. Bazylak, D. Sinton, N. Djilali, J. Power Sources 176 (2008) 240-246.

45. P.K. Sinha, P.P. Mukherjee and C.Y. Wang, J Materials Chemistry, Vol.17, pp.3089 (2007).

46. J. Park, M. Matsubara, and X. Li, Journal of Power Sources, 173: 404-414 (2007).

47. Y. Wang, S. Cho, R. Thiedmann, V. Schmidt, W. Lehnert, X. Feng, International Journal of Heat and Mass Transfer, 53 (2010) 1128-1138. 
48. Y. Wang and M. Gundevia, Measurement of thermal conductivity and heat pipe effect in hydrophilic and hydrophobic carbon papers. International Journal of Heat and Mass Transfer, 60, 134-142 (2013).

49. B. Zohuri, Heat pipe design and technology: A practical approach. CRC Press, 2011.

50. Y. Wang and K.S. Chen, Elucidating two-phase transport in a polymer electrolyte fuel cell, Part 1: characterizing flow regimes with a dimensionless group, Chemical Engineering Science 66 (2011) 3557-3567.

51. W.M. Kays, M.E. Crawford, B. Weigand, W. Kays, and M. Crawford, Convective Heat and Mass Transfer, 4th Edition, McGraw-Hill Inc., 2004.

52. M. Koz and S.G. Kandlikar, Numerical simulation of the interfacial oxygen transport resistance for a PEMFC cathode incorporating water droplet coverage. ECS Trans 2012;50:183e96.

53. M.A. Hickner, N.P. Siegel, K.S. Chen, D.S. Hussey, D.L. Jacobson, M. Arif, J. Electrochem. Soc. 155, B427-B434 (2008).

54. J.H. Nam, K.J. Lee, G.S. Hwang, C.J. Kim, and M. Kaviany, Microporous Layer for Water Morphology Control in PEMFC. Int. J. Heat Mass Transfer, 52 (2009) 2779-2791. 


\section{List of the tables}

Table 1. Geometrical, physical and operating parameters.

Table 2. Source terms of several conservation equations.

Table 3. Electrochemical properties. 
Table 1. Geometrical, physical and operating parameters

\begin{tabular}{ll}
\hline Quantity & Value \\
\hline Channel depth/width and land width & $0.5 / 1.5$ and $1.0 \mathrm{~mm}$ \\
GDL/Catalyst layer/Membrane thickness & $0.2 / 0.01 / 0.03 \mathrm{~mm}$ \\
Anode/cathode pressures, $\mathrm{P}$ & $2.0 / 2.0 \mathrm{~atm}$ \\
Porosity of GDLs/catalyst layers, $\varepsilon$ & $0.6 / 0.4$ \\
Humidification in the anode and cathode & $100 / 100 \%$ \\
Volume fraction of ionomer in catalyst layers, $\varepsilon_{m}$ & 0.23 \\
Electronic conductivity of GDLs/bipolar plates, $\sigma_{s}^{e f f}$ & $500 / 2000 \mathrm{~W} \mathrm{~m} \mathrm{~K}^{-1}$ \\
Viscosity of liquid water, $\mu_{l}$ & $3.5 \times 10^{-4} \mathrm{~kg} / \mathrm{m} \mathrm{s}^{-20} \mathrm{~m}^{2}$ \\
Permeability of GDL/membrane, $K_{G D L} / K_{m}$ & $10^{-12} / 5 \times 10^{-2}$ \\
Surface tension, liquid-water-air, $\sigma$ & $0.0625 \mathrm{~N} / \mathrm{m}^{-1}$ \\
Thermal conductivity of GDLs & $1.7 / 1.0 \mathrm{~W} / \mathrm{m} \mathrm{K}^{-3}$ \\
Thermal conductivity of the membrane/CL/BP & $0.95 / 3.0 / 100.0 \mathrm{~W} / \mathrm{m} \mathrm{K}$ \\
Contact angle of the GDL, $\theta_{c}$ & $120^{\circ}$ \\
Exchange current density $\times$ reaction surface area, $a_{0} i_{0, a} / a_{0} i_{0, c}$ & $1.0 \times 10^{9} / 1.0 \times 10^{4}$ \\
\hline
\end{tabular}


Table 2. Source terms of the governing equations.

\begin{tabular}{|c|c|c|c|c|}
\hline & $S_{u}$ & $S_{C^{k}}$ & $S_{C^{\prime \prime}}$ & $S_{\Phi^{(m)}} / S_{\Phi^{(s)}}$ \\
\hline Bipolar plates & - & $-/$ & $-/-$ & $-/ 0$ \\
\hline Gas channels & $-\nabla P$ & 0 & 0 & - \\
\hline GDL & $-\frac{\mu}{K_{G D L}} \vec{u}$ & 0 & 0 & $-/ 0$ \\
\hline $\begin{array}{c}\text { Anode } \\
\text { catalyst layer }\end{array}$ & $-\frac{\mu}{K_{C L}} \vec{u}$ & $-\frac{j}{2 F}$ & $-\nabla \cdot\left(\frac{n_{d}}{F} i_{e}\right)$ & $j /-j$ \\
\hline $\begin{array}{l}\text { Cathode } \\
\text { catalyst layer }\end{array}$ & $-\frac{\mu}{K_{C L}} \vec{u}$ & $\frac{j}{4 F}$ & $-\nabla \cdot\left(\frac{n_{d}}{F} i_{e}\right)-\frac{j}{2 F}$ & $j /-j$ \\
\hline Membrane & - & 0 & 0 & $0 /-$ \\
\hline The considered & $\begin{array}{r}\text { chemical } \\
\text { (An } \\
\text { (Cat }\end{array}$ & $\begin{array}{r}\mathrm{n} \text { PEN } \\
\mathrm{H}_{2}- \\
2 \mathrm{H}_{2} \\
\end{array}$ & $\begin{array}{l}\text { ells are: } \\
2 \mathrm{e}^{-} \\
-4 \mathrm{H}^{+}=4 \mathrm{e}^{-}\end{array}$ & \\
\hline
\end{tabular}


Table 3. Electrochemical properties.

\begin{tabular}{ccc}
\hline Description & Anode & Cathode \\
\hline $\begin{array}{c}\text { Transfer current } \\
\text { density, } j\left(\mathrm{~A} / \mathrm{m}^{3}\right)\end{array}$ & $a i_{0, a}\left(\frac{C_{\mathrm{H} 2}}{C_{\mathrm{H} 2, \text { ref }}}\right)^{1 / 2}\left(\frac{\alpha_{a}+\alpha_{c}}{R T} \cdot F \cdot \eta\right)$ & $-a i_{0, c}\left(\frac{C_{\mathrm{O} 2}}{C_{\mathrm{O} 2, \text { ref }}}\right) \exp \left(-\frac{\alpha_{c} F}{R T} \cdot \eta\right)$ \\
$\begin{array}{c}\text { Surface overpotential, } \\
\eta(\mathrm{V})\end{array}$ & $\Phi_{s}-\Phi_{e}-U_{o}$ & $\Phi_{s}-\Phi_{e}-U_{o}$ \\
$\begin{array}{c}\text { Equilibrium potential, } \\
U_{o}(\mathrm{~V})\end{array}$ & 0 & $1.23-0.9 \times 10^{-3}(T-298)$ \\
$\begin{array}{c}\text { Exchange current } \\
\text { density x reaction } \\
\text { surface area, } a_{0} i_{0} \\
\left(\mathrm{~A} / \mathrm{m}^{3}\right)\end{array}$ & $1.0 \mathrm{x} 10^{9}$ & $10^{4}$ \\
Transfer coefficient, $\alpha$ & $\alpha_{a}+\alpha_{c}=2$ & $\alpha_{c}=1$ \\
\hline
\end{tabular}




\section{List of the figures}

1. Figure 1. A straight-channel fuel cell and water condensation in gas flow channels (a); and the computational meshes (b) 35

2. Figure 2. $\frac{d C_{s a t}^{w}}{d T}$ and $C_{s a t}^{w}$ as a function of temperature. 36

3. Figure 3. (i) Liquid saturation in the GDL and (ii) temperature distributions under the GDL thermal conductivity of $1.7 \mathrm{~W} / \mathrm{m} \mathrm{K}$; (iii) temperature and (iv) liquid water distributions under the GDL thermal conductivity of $1.0 \mathrm{~W} / \mathrm{m} \mathrm{K}$ at $80{ }^{\circ} \mathrm{C}$ and $0.5 \mathrm{~A} / \mathrm{cm}^{2}$ for three locations (dimensionless distance from the inlet): (a). 10\%; (b). 50\%; and (c). $90 \%$.

4. Figure 4. Liquid water in catalyst layer (CL), MPL, and GDL [54]. 38

5. Figure 5. Liquid water distributions in the GDL at (i) $60{ }^{\circ} \mathrm{C}$ and (ii) $90{ }^{\circ} \mathrm{C}$ under $0.5 \mathrm{~A} / \mathrm{cm}^{2}$ and the GDL thermal conductivity of $1.7 \mathrm{~W} / \mathrm{m} \mathrm{K}$; and (iii) liquid water in the GDL and (iv) temperature distributions at $90{ }^{\circ} \mathrm{C}, 1.0 \mathrm{~A} / \mathrm{cm}^{2}$, and the GDL thermal conductivity of $1.7 \mathrm{~W} / \mathrm{m} \mathrm{K}$ for three locations (dimensionless distance from the inlet): (a). $10 \%$; (b). $50 \%$; and (c). $90 \%$.

6. Figure 6. Water-vapor phase concentration (a) and temperature (b) distributions in the GDLs at the channel mid-plane under $90{ }^{\circ} \mathrm{C}, 0.5 \mathrm{~A} / \mathrm{cm}^{2}$, and the GDL thermal conductivity of $1.7 \mathrm{~W} / \mathrm{m} \mathrm{K}$. In (a), the region between the dashed line near the cathode MEA and the MEA (represented by the blue bold line) is in two-phase region.

7. Figure 7. (i) Net water transfer coefficients $\alpha$ under the channel and (ii) current density distribution for the operating temperatures of: (a) $60{ }^{\circ} \mathrm{C}$; (b) $80{ }^{\circ} \mathrm{C}$; and 
(c) $90{ }^{\circ} \mathrm{C}$ at the current density of $0.5 \mathrm{~A} / \mathrm{cm}^{2}$ and GDL thermal conductivity of 1.7

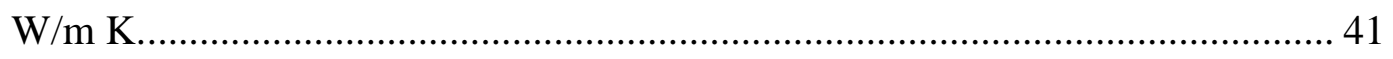

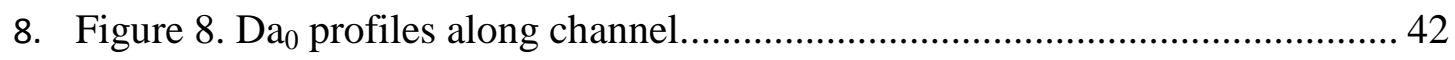



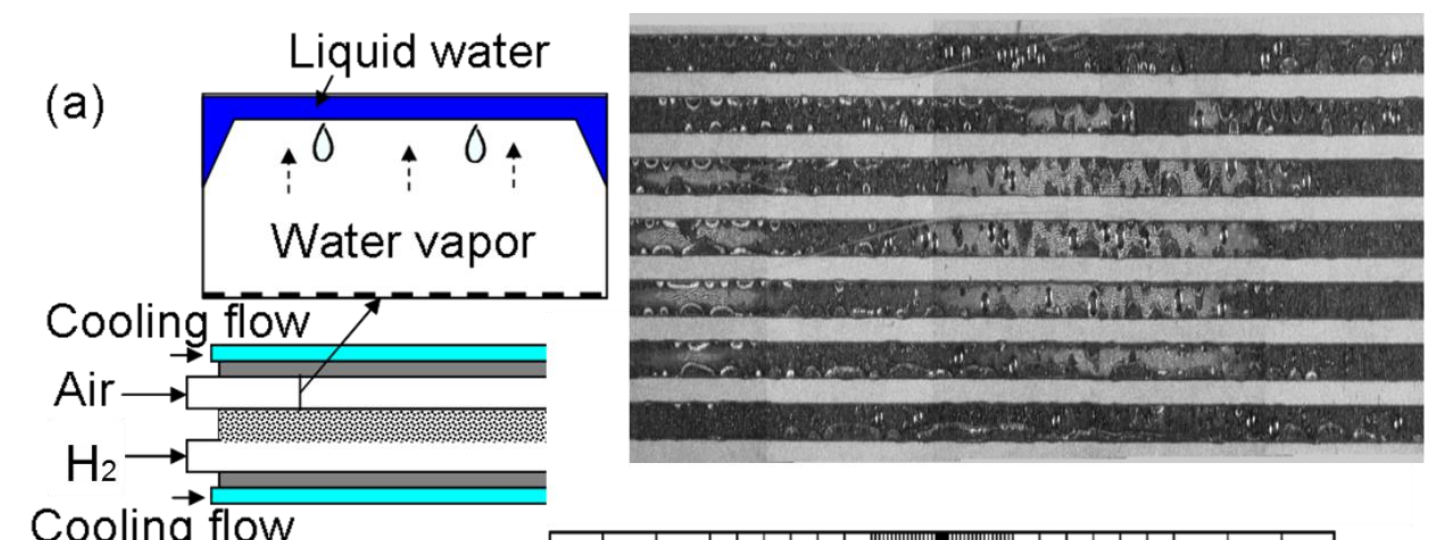

Cooling flow

(b)
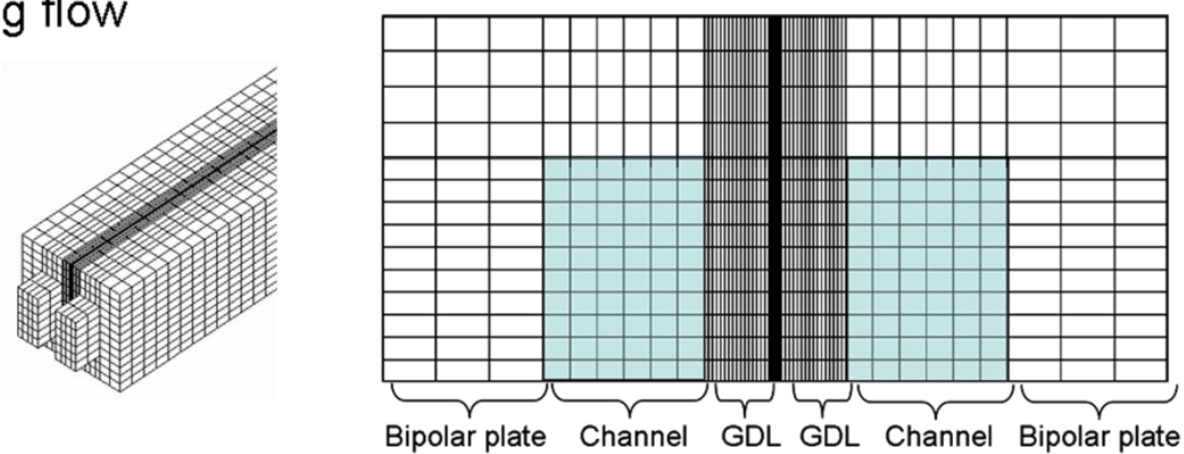

28

29

30

31 


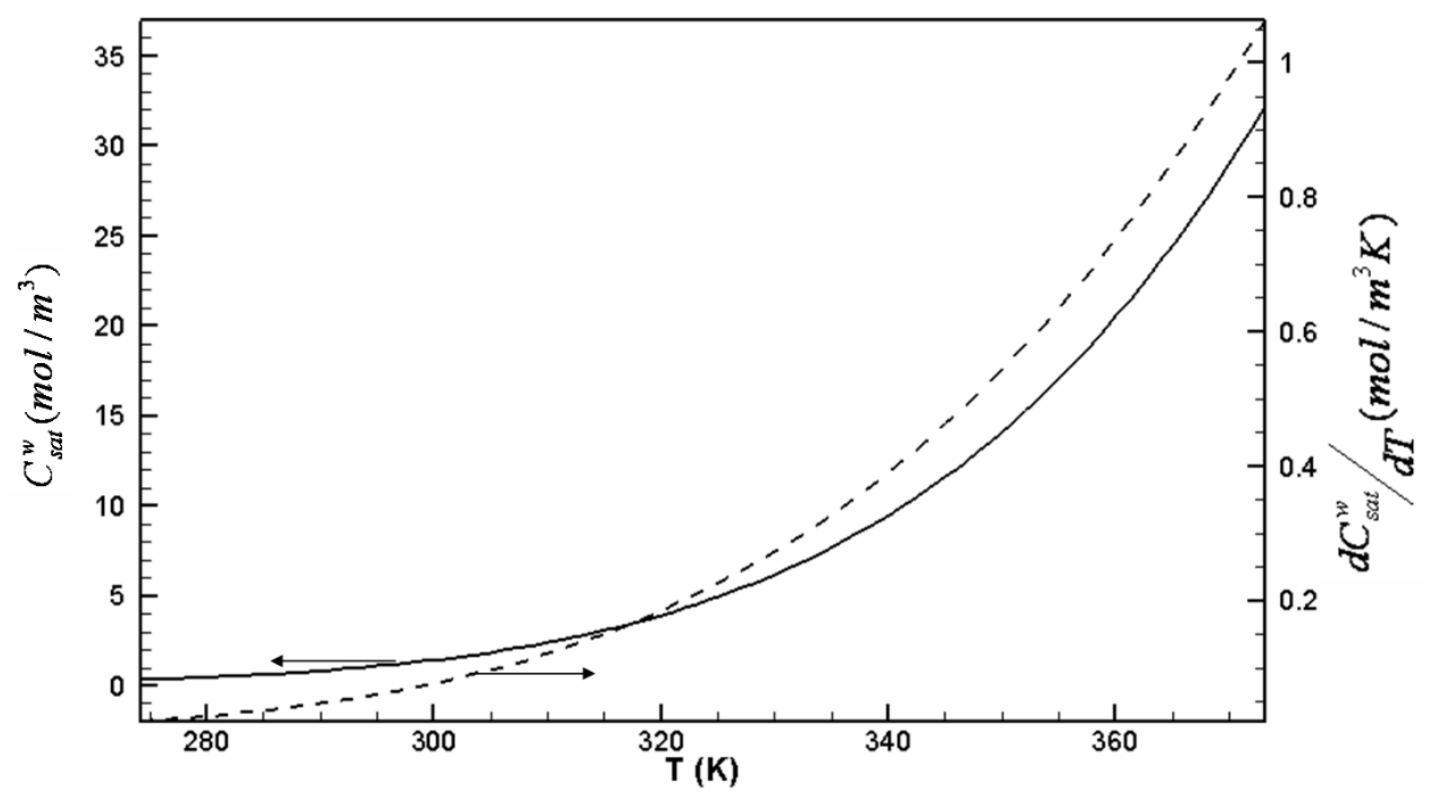

Figure 2. $\frac{d C_{s a t}^{w}}{d T}$ and $C_{s a t}^{w}$ as a function of temperature. 


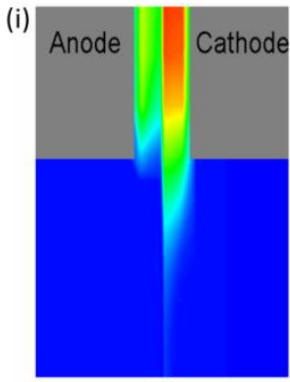

(a)

(ii)
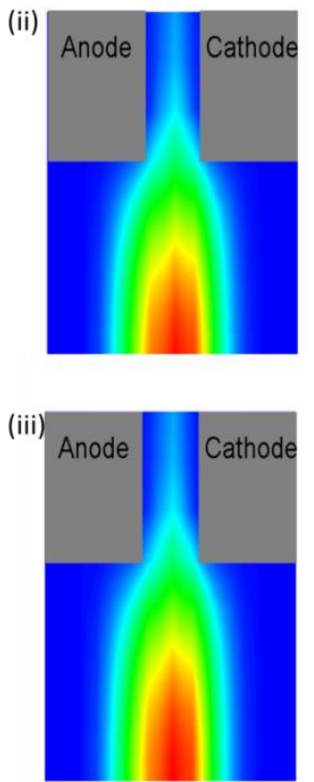

(a)

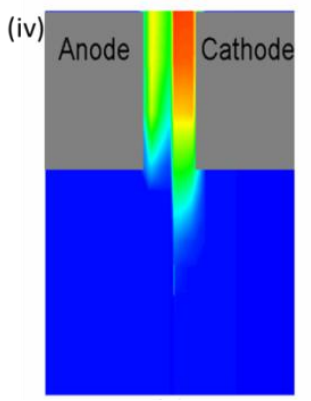

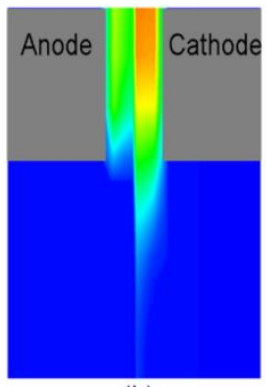

(b)
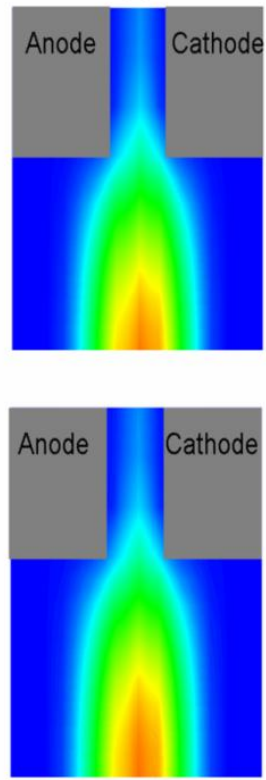

(b)

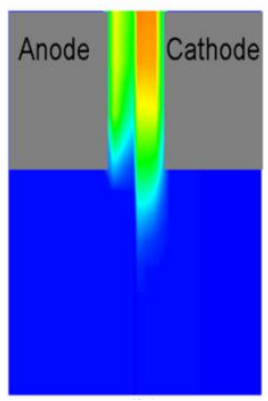

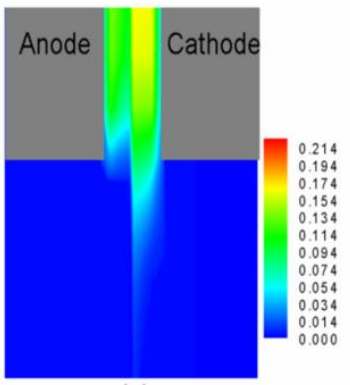

(c)
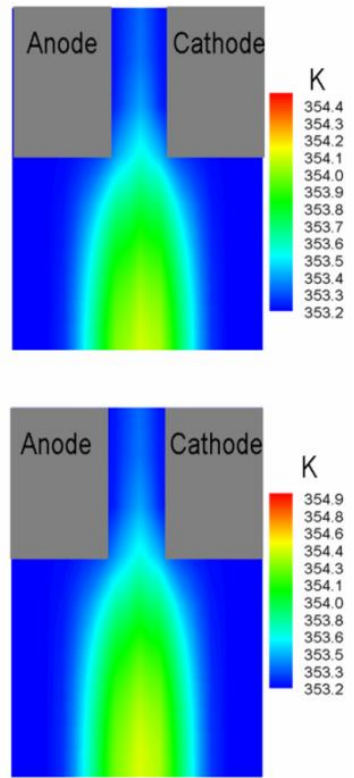

(c)

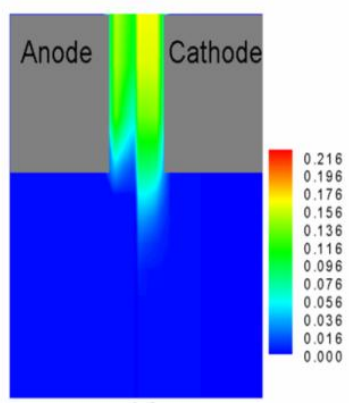

Figure 3. (i) Liquid saturation in the GDL and (ii) temperature distributions under the GDL thermal conductivity of $1.7 \mathrm{~W} / \mathrm{m} \mathrm{K}$; (iii) temperature and (iv) liquid water distributions under the GDL thermal conductivity of $1.0 \mathrm{~W} / \mathrm{m} \mathrm{K}$ at $80{ }^{\circ} \mathrm{C}$ and $0.5 \mathrm{~A} / \mathrm{cm}^{2}$ for three locations (dimensionless distance from the inlet): (a). 10\%; (b). 50\%; and (c). $90 \%$. 
(a) Vapor Condensation and Liquid Water Breakthrough in CL

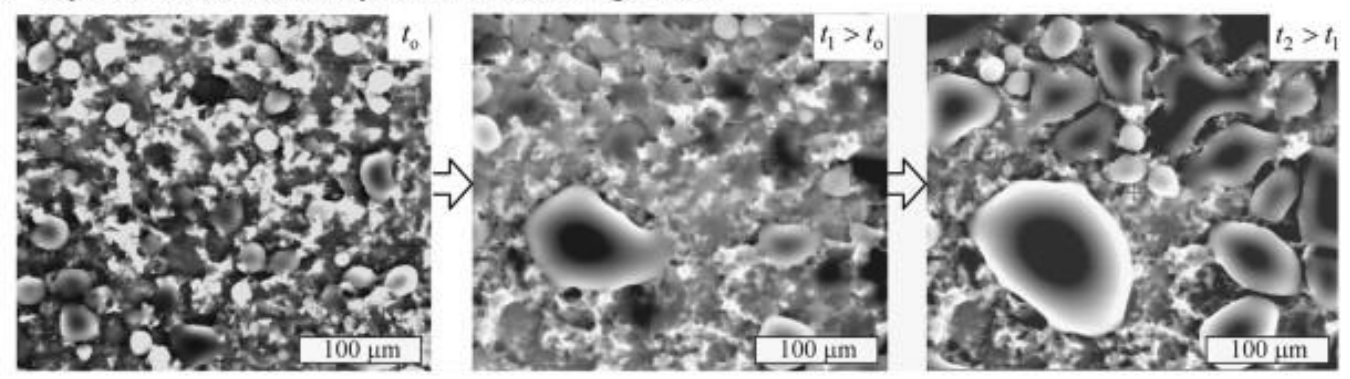

(b) Vapor Condensation and Liquid Water Breakthrough in MPL
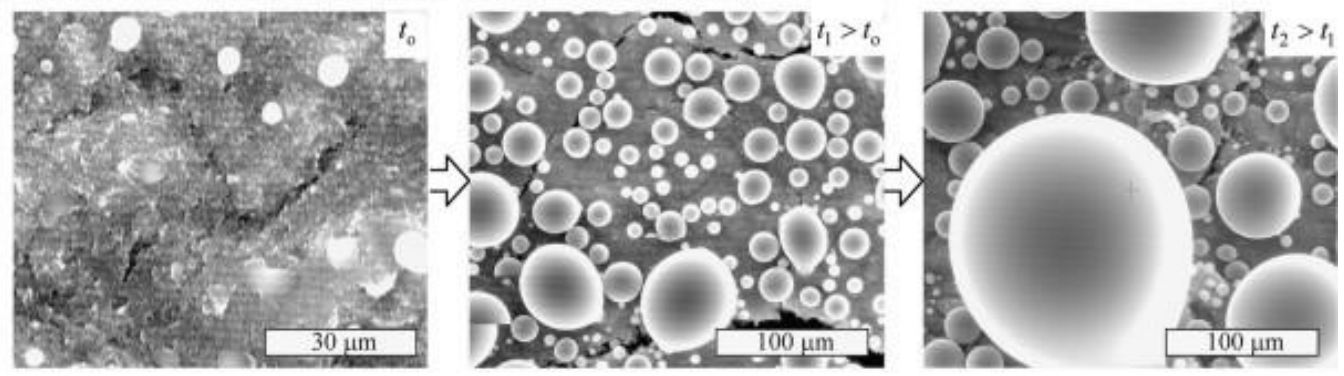

(c) Vapor Condensation and Liquid Water Breakthrough in GDL
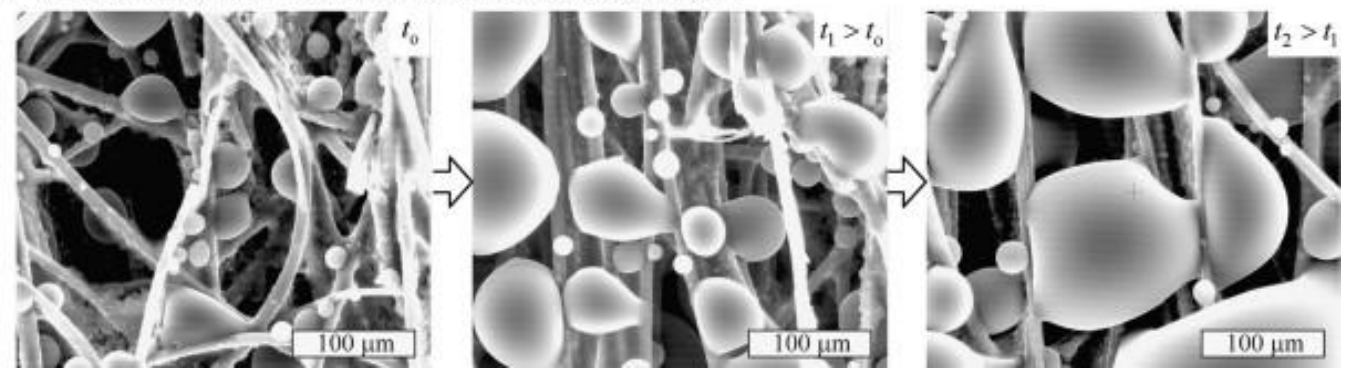

Figure 4. Liquid water in catalyst layer (CL), MPL, and GDL [54]. 


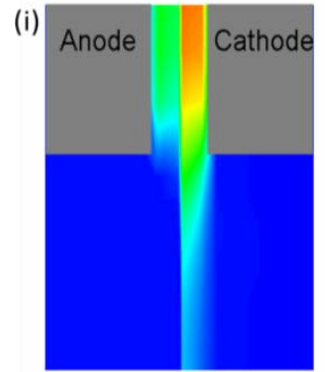

(a)

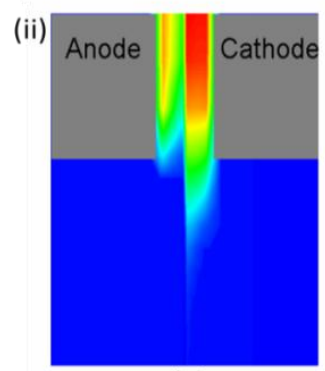

(iii)

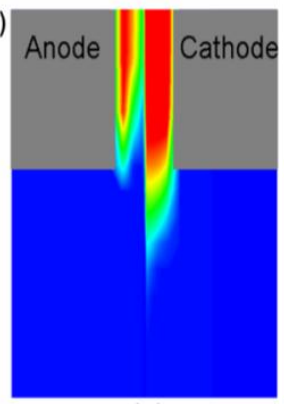

(a)

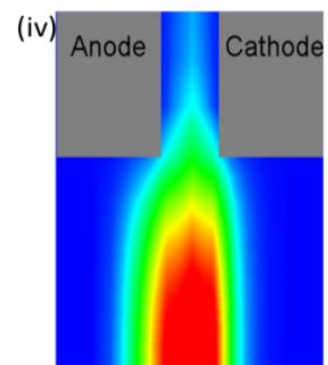

(a)

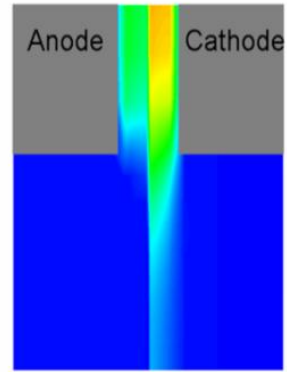

(b)
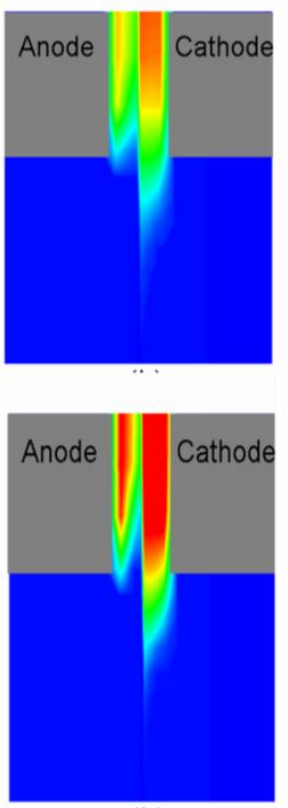

(b)

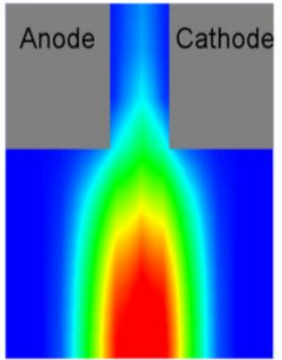

(b)

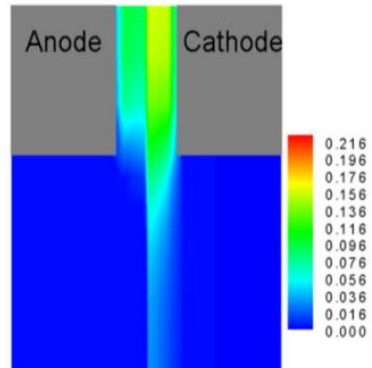

(c)
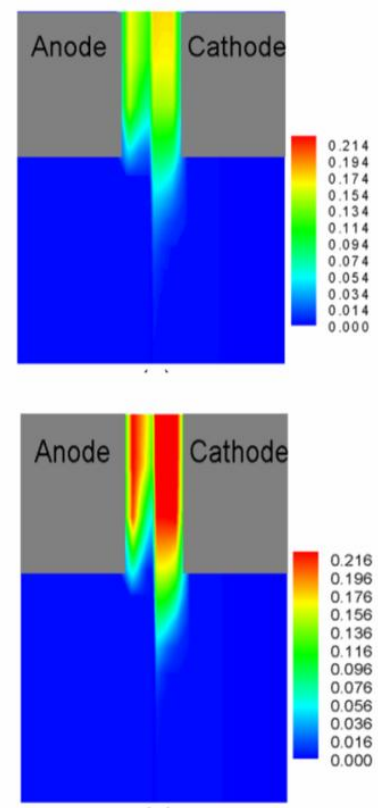

(c)

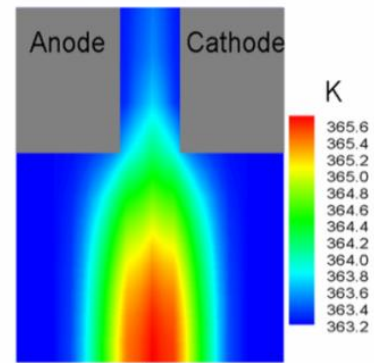

(c)

Figure 5. Liquid water distributions in the GDL at (i) $60{ }^{\circ} \mathrm{C}$ and (ii) $90{ }^{\circ} \mathrm{C}$ under 0.5 $\mathrm{A} / \mathrm{cm}^{2}$ and the GDL thermal conductivity of $1.7 \mathrm{~W} / \mathrm{m} \mathrm{K}$; and (iii) liquid water in the GDL and (iv) temperature distributions at $90{ }^{\circ} \mathrm{C}, 1.0 \mathrm{~A} / \mathrm{cm}^{2}$, and the GDL thermal conductivity of $1.7 \mathrm{~W} / \mathrm{m} \mathrm{K}$ for three locations (dimensionless distance from the inlet): (a). 10\%; (b).

$$
50 \% \text {; and (c). } 90 \% \text {. }
$$




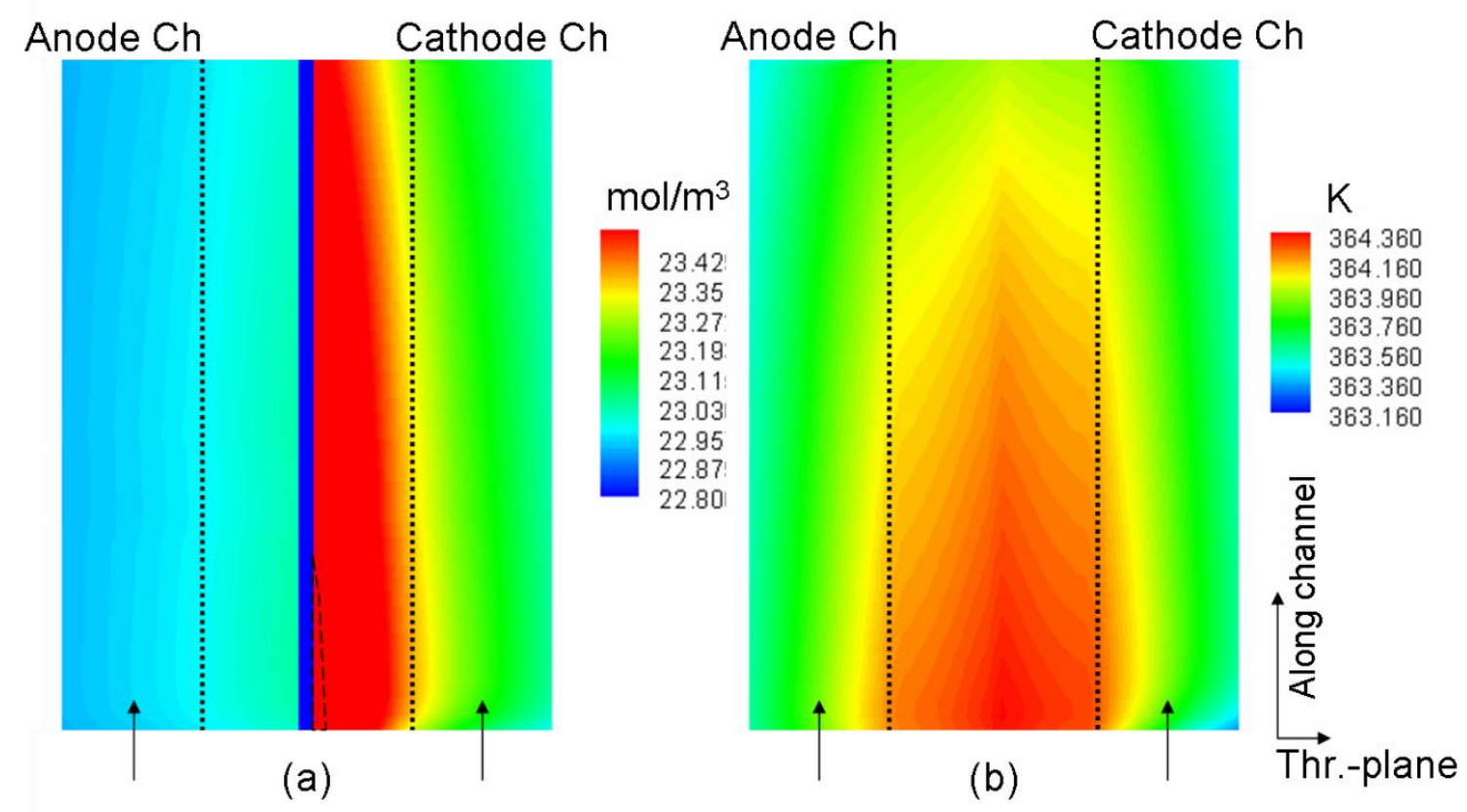

Figure 6. Water-vapor phase concentration (a) and temperature (b) distributions in the GDLs at the channel mid-plane under $90{ }^{\circ} \mathrm{C}, 0.5 \mathrm{~A} / \mathrm{cm}^{2}$, and the GDL thermal conductivity of $1.7 \mathrm{~W} / \mathrm{m} \mathrm{K}$. In (a), the region between the dashed line near the cathode MEA and the MEA (represented by the blue bold line) is in two-phase region. 
(i)

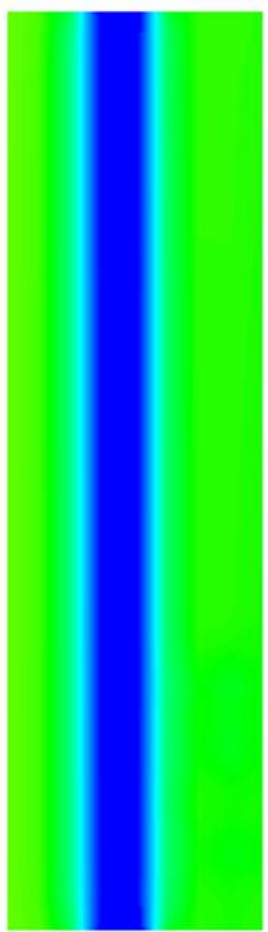

(a)

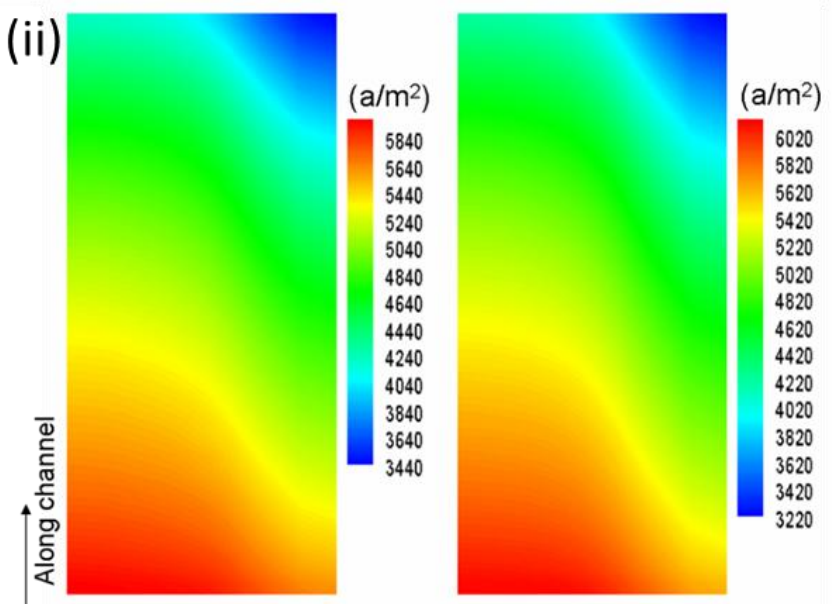

(b)
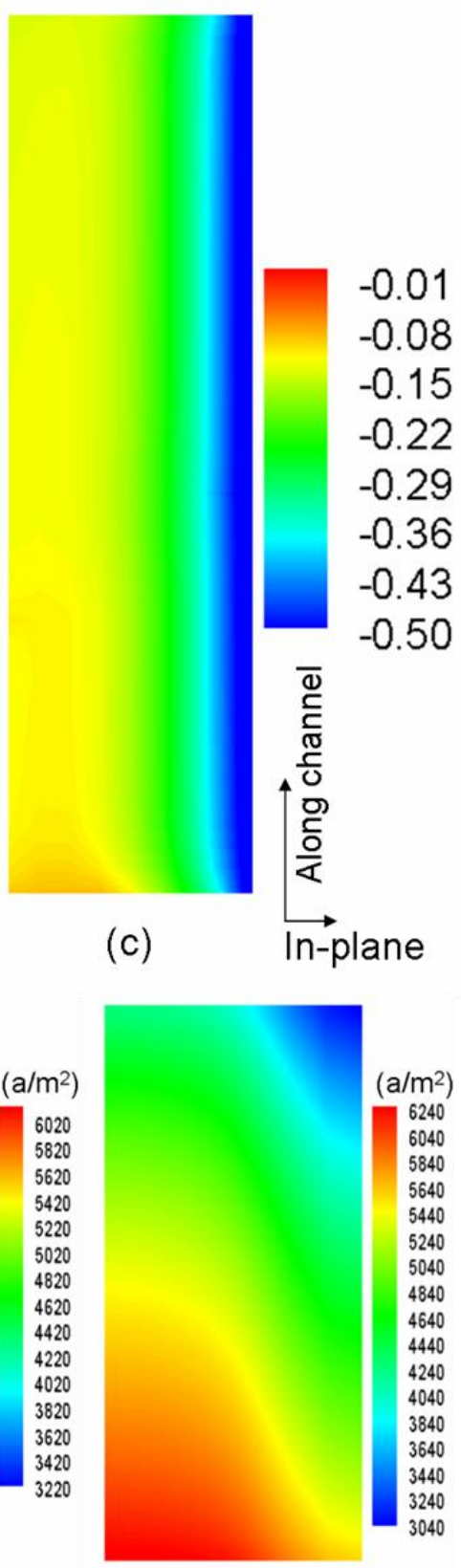

(c)

Figure 7. (i) Net water transfer coefficients $\alpha$ under the channel and (ii) current density distribution for the operating temperatures of: (a) $60{ }^{\circ} \mathrm{C}$; (b) $80{ }^{\circ} \mathrm{C}$; and (c) $90{ }^{\circ} \mathrm{C}$ at the current density of $0.5 \mathrm{~A} / \mathrm{cm}^{2}$ and GDL thermal conductivity of $1.7 \mathrm{~W} / \mathrm{m} \mathrm{K}$. 


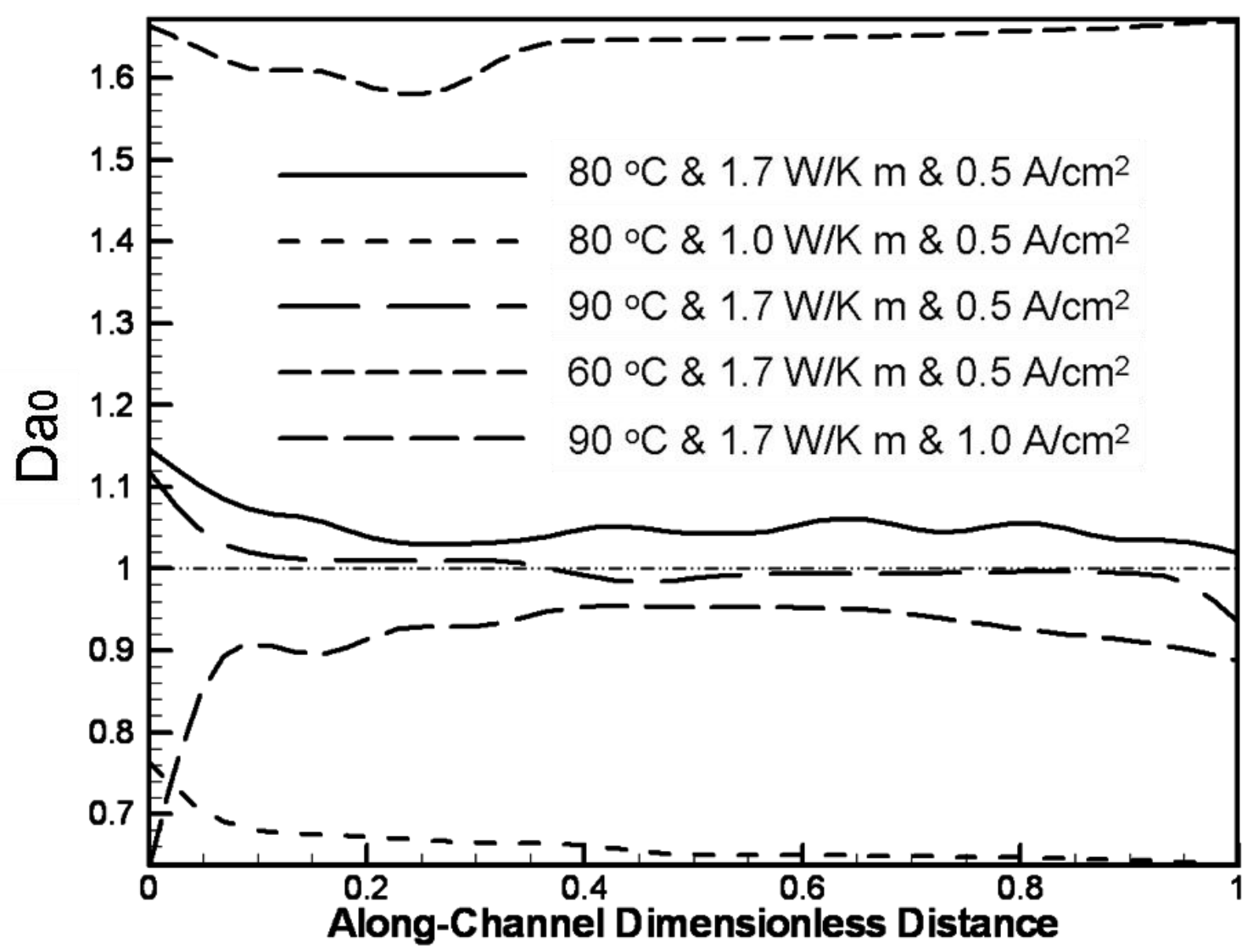

Figure 8. $\mathrm{Da}_{0}$ profiles along channel. 